\title{
Giving Opens The Way For Receiving!! ... A Microscopic View Into Selection Of Tea Brand In India
}

\author{
${ }^{1}$ Dr. Gayathri Band, Shri Ramdeobaba College of Engineering and Management, Nagpur \\ ${ }^{2}$ Dr. Neeta V Sahh, Shri Ramdeobaba College of Engineering and Management, Nagpur \\ ${ }^{3}$ CA (Dr). Manish N Shah, G H Raisioni College of Commerce Science \& Technology, Nagpur \\ ${ }^{4}$ Prof. Jyoti Samseriya, G H Raisioni College of Commerce Science \& Technology, Nagpur
}

\begin{abstract}
Tea has played a role in almost all cultures and customs. The Indian Tea Industry is about 176 years old. Satisfying customers' wishes is a challenge for many companies in the today's rapidly changing and keenly competitive environment in today's Tea industry. In this experiment with, seven product attributes of tea where each attribute has three performance levels have been designed for conjoint analysis. The first influencing factor is the preference of the type of tea where packaged tea has the highest utility as it captures the maximum of Tea market in India as compared to loose or tea bags which are mostly not preferred by the consumers. As consumers are very loyal towards the Tea brand which they purchase and hence we can see the most important criterion or influencing factor while selection of tea is the Brand name followed by the family opinion as traditionally the family believes to have a good taste of tea which should act a stimulant and psychological preference and family preference does matter when purchasing a tea. The pricing is the fourth important factor influencing the choice of tea. The most preferred attributes for tea are Variety of tea should be leaf with medium pricing where selection criterion of tea is good taste and brand name influences the consumer the highest and Tea should preferably be present at all General Store Outlets and preferred convenient packaging for consumers is Carton Boxes.
\end{abstract}

Keywords: Consumer Preference; Customer Value; Conjoint Analysis; CART Analysis; Perceptual Mapping; Tea Article Received: 10 August 2020, Revised: 25 October 2020, Accepted: 18 November 2020

\subsection{INTRODUCTION}

Tea has played a role in almost all cultures and customs. The Indian Tea Industry is about 176 years. The fulfillment of customers' wishes in a profitable way requires that companies understand which aspects of their product and service are most valued by the customer. A thorough knowledge of customer needs is even considered to be the foundation on which a company is built (MohrJackson, 1996). It's an important task of a company's marketing department is to create a profit maximizing bundle of product or service attributes or in other words a profit maximizing value proposal. The main question which has to be answered is - how to use the limited resources of the company in product and service design and development to maximize its profit.

\subsection{LITERATURE REVIEW}

For understanding customer needs and studying them systematically it is necessary to be familiar with the concept of creating value to the customer. Walters and Lancaster (1999) have stated that value is created by any product or service attribute, which motivates the customer to buy the product and takes him closer to achieving his goals. Attributes of a product or service that create value to customers can be divided into (Woodall, 2003):

1) Factors that enhance customer's benefits or help to satisfy his needs,

2) Factors that decrease customer's costs.

It is pointed out that brand can create value to customers (Best, 2002). And of course there usually are industry specific factors that customers perceive as valuable. Customers usually name many factors as needs. It is reasonable to organize them into a hierarchic structure - as the first order, secondary and if necessary also the third level needs. To estimate the importance of customers' needs most frequently simple 5- or 7-point rating 
scales are used. Often, the result is that customers consider most of factors identically "extremely important" (Gale, Wood, 1994).

\subsection{RESEARCH METHODOLOGY}

Total respondents of 150 were selected consisting of Consumers, Retailers, Distributors, C\&F, Employees involved in the Tea Brand distribution chain to whom the Questionnaire has been administered and relevant information through Interview process face to face, skype and telephonic process with each was done to collect the relevant information for the research paper.

In our research paper we have focused on psychographic \& behavioral segmentation variables using Conjoint Analysis followed by CART Analysis (Decision tree) to understand perceptual mapping to understand the important brand and the attribute contemplated by the consumers and retailers with respect to tea in India

\subsection{OBJECTIVE:}

- To study the factors effecting the consumers when choosing the tea brand

- To study the market preference of the tea brands and what strategy to used when entering the market

- To study the factors effecting the retailer perception when selling tea product The factors effecting the purchase decision of the consumers when choosing the tea brand.

\section{Figure 1: BRAND RECALL}

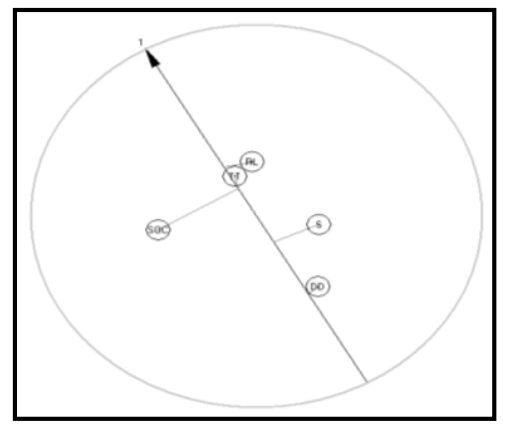

With respect to Brand Recall Attribute the highest and closest to vector is Red Label
- Understanding the customer specifications for increasing the customer value towards a Tea Brand.

\subsection{DATA ANALYSIS \\ 4.1 FACTORS AFFECTING CONSUMERS' CHOICE}

To study the first three objectives PerMap software has been used and the results are as follows:

Two things are observed:

(1) The objective function is which is also known as error function, it bespeaks how distant the objects are from a good configuration. When multiple points are plotted on the perceptual map, we may not be able to correct the distance between them. There is always a scope of error which is indicated by Objective Function Value. The software by default diminishes this error. The objective function value for attribute rating for retailers is 0.023880 . The value of $R^{2}$ for this attribute rating is 0.955

(2) In Permap the characteristic which are tested for are the vectors. The arrows are called attribute vectors which shows the direction in which the magnitude of that particular vector is increasing. The radius of an object from the arrow indicates how closely it is related to that characteristic. Had there been only one characteristic which is tested for then all the object would be on the same vector line. Since many attributes are tested at once the alignment of objects is adjusted to indicate its closeness correctly to each every vector attributes.

Figure 2: CONSUMER OFFERS

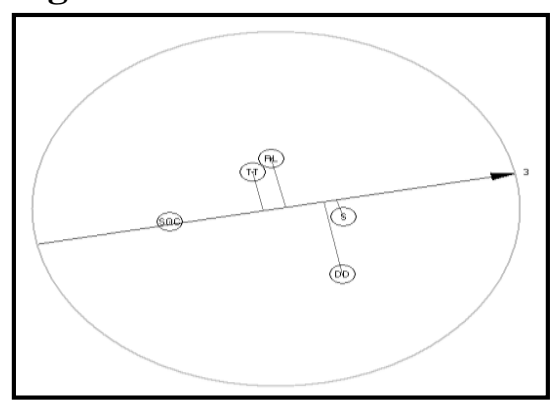

With respect to Consumer Offers Attribute the highest and closest to vector is Wagh Bakri 
followed by Tata Tea, Society, Wagh Bakri and Double Diamond.

Figure 3: PRICE

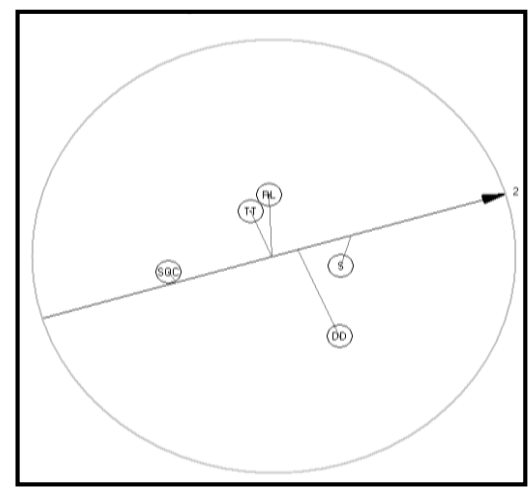

With respect to Price Attribute the highest and closest to vector is Wagh Bakri followed by Double Diamond, Red Label, Tata Tea, and Society.

\section{Figure 5: INNOVATION IN PRODUCT}

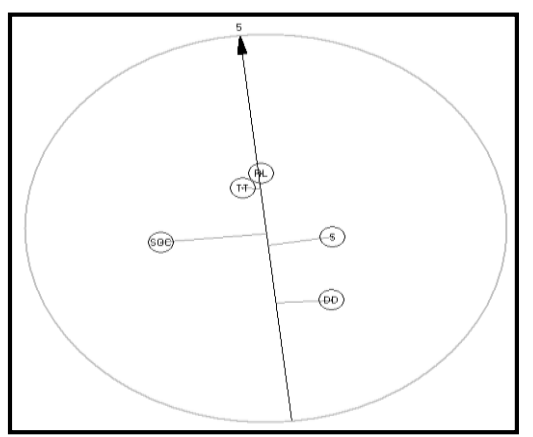

With respect to Innovation in Product Attribute the highest and closest to vector is Red Label followed by Tata Tea, Society, Wagh Bakri and Double Diamond.

\section{Figure 7: QUALITY}

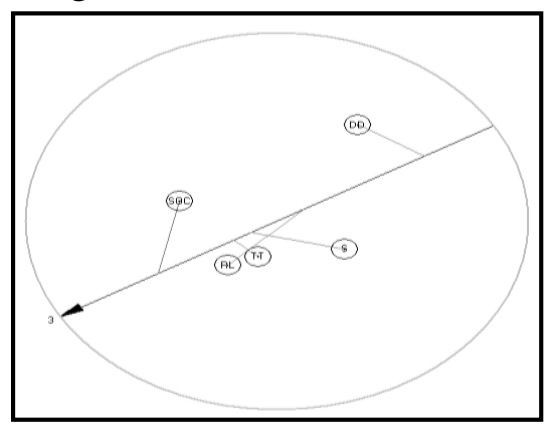

With respect to Quality Attribute the highest and closest to vector is Society followed by Tata Tea, Wagh Bakri, Red Label, and Double Diamond. followed by Double Diamond, Red Label, Tata Tea, and Society.

\section{Figure 4: RETAILER OFFERS}

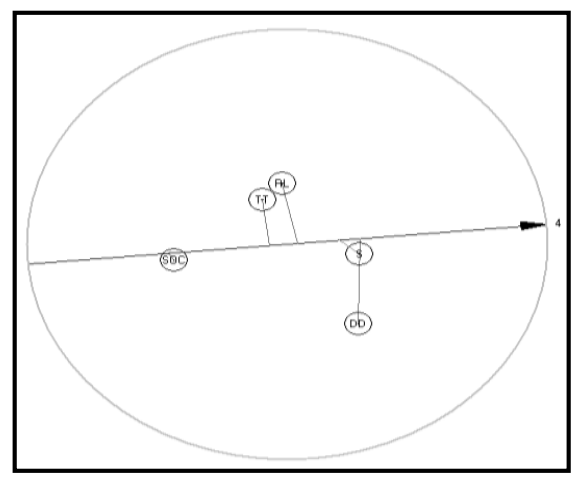

With respect to Retail Offers Attribute the highest and closest to vector is Double Diamond followed by Wagh Bakri, Red Label, Tata Tea, and Society.

\section{Figure 6: VARIETY}

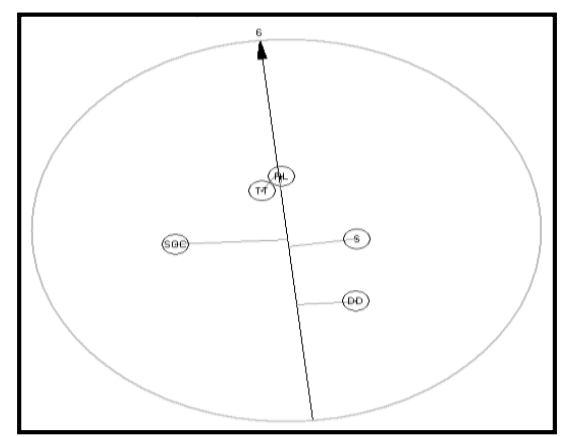

With respect to Variety of Product Attribute the highest and closest to vector is Red Label followed by Tata Tea, Society, Wagh Bakri and Double Diamond.

\section{Figure 8: PACKAGING}

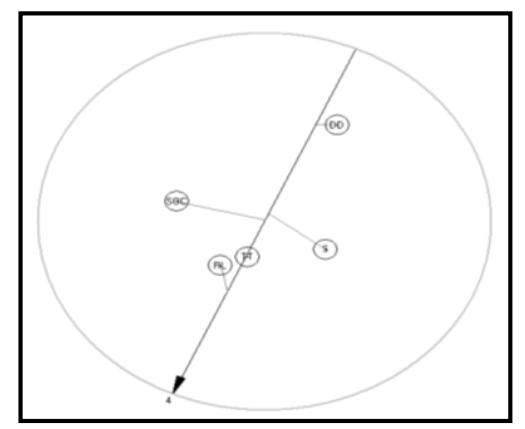

With respect to Packaging of Product Attribute the highest and closest to vector is Red Label followed by Tata Tea, Society, Wagh Bakri and Double Diamond. 
Figure 9: AVAILABILITY

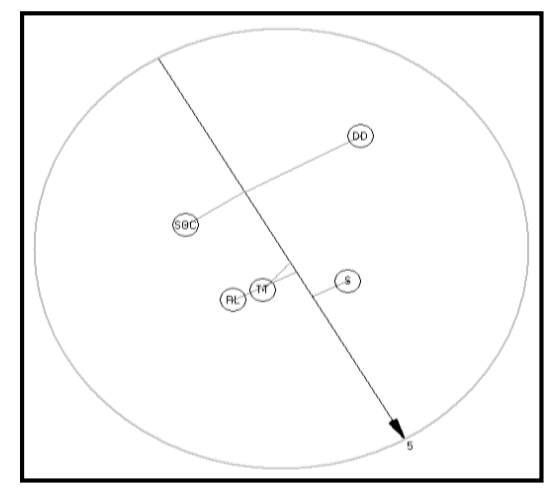

With respect to Availability Attribute the highest and closest to vector is Wagh Bakri followed by Red Label, Tata Tea, Society, and Double Diamond
Figure 10: BRAND LOYALTY

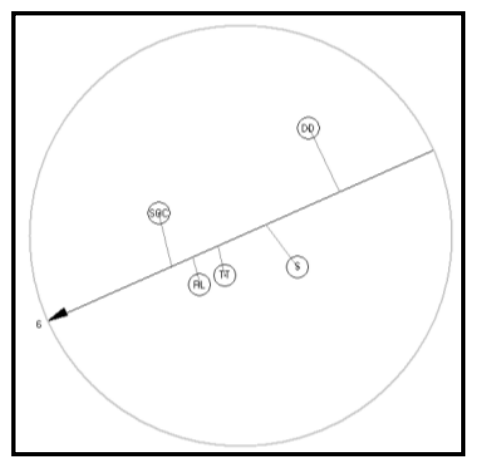

With respect to Loyalty towards the brand Attribute the highest and closest to vector is Society followed by Red Label, Tata Tea, Wagh Bakri, and Double Diamond.

\subsubsection{COMPILED ATTRIBUTE PREFERENCE FOR THE TEA BRANDS}

\begin{tabular}{|c|c|c|c|c|c|}
\hline ATTRIBUTES & $\begin{array}{c}\text { BRAND } \\
\text { RECALL }\end{array}$ & PRICE & $\begin{array}{c}\text { CONSUMER } \\
\text { OFFERS }\end{array}$ & $\begin{array}{l}\text { RETAIL } \\
\text { OFFERS }\end{array}$ & $\begin{array}{c}\text { INNOVATION } \\
\text { IN PDT }\end{array}$ \\
\hline $1^{\mathrm{ST}}$ RANK & RED LABEL & $\begin{array}{l}\text { WAGH } \\
\text { BAKRI }\end{array}$ & WAGH BAKRI & $\begin{array}{l}\text { DOUBLE } \\
\text { DIAMOND }\end{array}$ & RED LABEL \\
\hline $\mathbf{2}^{\mathrm{ND}}$ RANK & TATA TEA & $\begin{array}{l}\text { DOUBLE } \\
\text { DIAMOND }\end{array}$ & $\begin{array}{l}\text { DOUBLE } \\
\text { DIAMOND }\end{array}$ & WAGH BAKRI & TATA TEA \\
\hline $3^{\mathrm{RD}}$ RANK & SOCIETY & RED LABEL & RED LABEL & RED LABEL & SOCIETY \\
\hline $4^{\mathrm{TH}}$ RANK & $\begin{array}{l}\text { WAGH } \\
\text { BAKRI }\end{array}$ & TATA TEA & TATA TEA & TATA TEA & WAGH BAKRI \\
\hline $5^{\mathrm{TH}}$ RANK & $\begin{array}{l}\text { DOUBLE } \\
\text { DIAMOND }\end{array}$ & SOCIETY & SOCIETY & SOCIETY & $\begin{array}{l}\text { DOUBLE } \\
\text { DIAMOND }\end{array}$ \\
\hline ATTRIBUTES & VARIETY & QUALITY & PACKAGING & AVAILABILITY & LOYALTY \\
\hline $1^{\mathrm{ST}}$ RANK & RED LABEL & SOCIETY & RED LABEL & WAGH BAKRI & SOCIETY \\
\hline $2^{\mathrm{ND}}$ RANK & TATA TEA & TATA TEA & TATA TEA & RED LABEL & RED LABEL \\
\hline $3^{\mathrm{RD}}$ RANK & SOCIETY & $\begin{array}{l}\text { WAGH } \\
\text { BAKRI }\end{array}$ & SOCIETY & TATA TEA & TATA TEA \\
\hline $4^{\mathrm{TH}}$ RANK & $\begin{array}{l}\text { WAGH } \\
\text { BAKRI }\end{array}$ & RED LABEL & WAGH BAKRI & SOCIETY & WAGH BAKRI \\
\hline $5^{\mathrm{TH}}$ RANK & $\begin{array}{l}\text { DOUBLE } \\
\text { DIAMOND }\end{array}$ & $\begin{array}{l}\text { DOUBLE } \\
\text { DIAMOND }\end{array}$ & $\begin{array}{l}\text { DOUBLE } \\
\text { DIAMOND }\end{array}$ & $\begin{array}{l}\text { DOUBLE } \\
\text { DIAMOND }\end{array}$ & $\begin{array}{l}\text { DOUBLE } \\
\text { DIAMOND }\end{array}$ \\
\hline
\end{tabular}

For every $1^{\text {st }}$ rank 10 points are allotted to brand, $2^{\text {nd }}$ rank 8 points and similarly $3^{\text {rd }}$ rank $6,4^{\text {th }}$ rank $4,5^{\text {th }}$ rank 2 points respectively. The table is represented below according to the points allotted.

\begin{tabular}{|l|c|c|c|c|c|}
\hline TEA BRAND & $\begin{array}{c}\text { BRAND } \\
\text { RECALL }\end{array}$ & PRICE & $\begin{array}{c}\text { CONSUMER } \\
\text { OFFERS }\end{array}$ & $\begin{array}{c}\text { RETAIL } \\
\text { OFFERS }\end{array}$ & $\begin{array}{c}\text { INNOVATION } \\
\text { IN PDT }\end{array}$ \\
\hline RED LABEL & 10 & 6 & 6 & 6 & 10 \\
\hline TATA TEA & 8 & 4 & 4 & 4 & 8 \\
\hline SOCIETY & 6 & 2 & 2 & 2 & 6 \\
\hline
\end{tabular}




\begin{tabular}{|l|c|c|c|c|c|}
\hline WAGH BAKRI & 4 & 10 & 10 & 8 & 4 \\
\hline $\begin{array}{l}\text { DOUBLE } \\
\text { DIAMOND }\end{array}$ & 2 & 8 & 8 & 10 & 2 \\
\hline TEA BRAND & VARIETY & QUALITY & PACKAGING & AVAILABILITY & LOYALTY \\
\hline RED LABEL & 10 & 4 & 10 & 8 & 8 \\
\hline TATA TEA & 8 & 8 & 8 & 6 & 6 \\
\hline SOCIETY & 6 & 10 & 6 & 4 & 10 \\
\hline WAGH BAKRI & 4 & 6 & 4 & 10 & 2 \\
\hline $\begin{array}{l}\text { DOUBLE } \\
\text { DIAMOND }\end{array}$ & 2 & 2 & 2 & 2 & 2 \\
\hline
\end{tabular}

\section{TOTAL TALLY POINTS ACHIEVED BY EACH BRAND ARE AS FOLLOWS:}

\begin{tabular}{|l|c|}
\hline TEA BRANDS & TOTAL SCORE \\
\hline RED LABEL & 78 \\
\hline TATA TEA & 64 \\
\hline SOCIETY & 54 \\
\hline WAGH BAKRI & 64 \\
\hline DOUBLE DIAMOND & 40 \\
\hline
\end{tabular}

As per attribute rating of the retailers Red Label is ranked first preference followed by close preference for Tata Tea and Wagh Bakri alike, the third in preference is Society and the last in preference is Double Diamond. Wagh Bakri has scored top ranks in price showing price as the penetration strategy to increase market share followed by importance on promotional strategies like consumer offers and retail offers and with good distribution network which ranked first among the brands in terms of availability of the brand in the retail outlets. Hence based on attribute rating we can conclude that competitive pricing, efficient and timely distribution network, promotional strategies for both consumers and retailers are driving factors for tea brands to increase the market share in India and offer tough competition to the top players in the Tea industry.

\subsubsection{RETAILER PERCEPTION OF THE CONSUMER'S PREFERENCE / REASONS WHILE PURCHASING A TEA BRAND}

Figure 11: Retailer perception of consumer preference

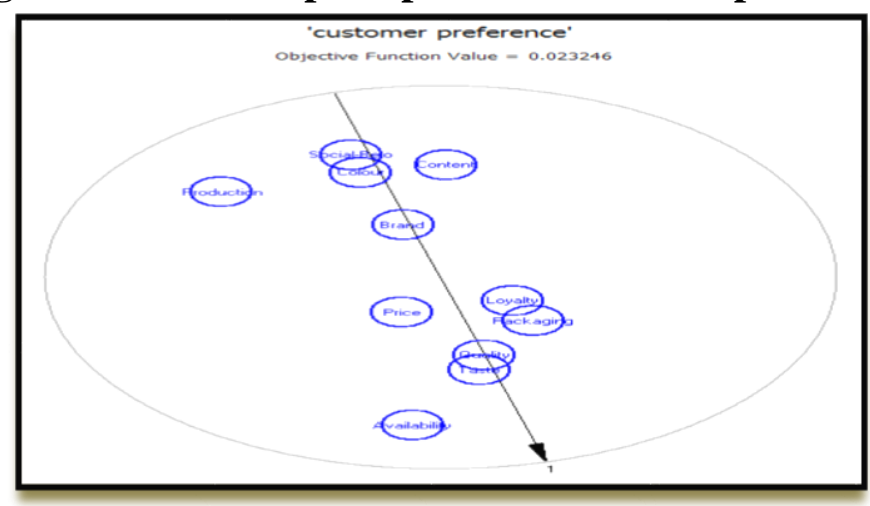


The objective function also known as error function, it indicates how distant the objects are from a good configuration. There is a scope of error which is indicated by Objective Function Value. The software by default minimises this error. The objective function value for attribute rating for retailers with respect to customers' preference for a particular tea brand is $\mathbf{0 . 0 2 3 2 4 6 .}$

The priority on which customer's preference of a particular tea brand from a retail outlet is as follows: Availability, Taste, Quality, Packaging, Loyalty, Price, Brand, Colour, Content, Production and Social belonginess. Most important areas which needs to be focused accordingly is availability and efficient distribution network, Quality of the product including taste and packaging is very important for any tea brand to sustain in the long run.

\subsubsection{FACTORS CONSIDERED IMPORTANT BEFORE TAKING A DECISION TO KEEP RANGE \& BRAND OF TEA IN THE RETAIL OUTLETS}

Figure 12: Retailer perception towards selling tea brands

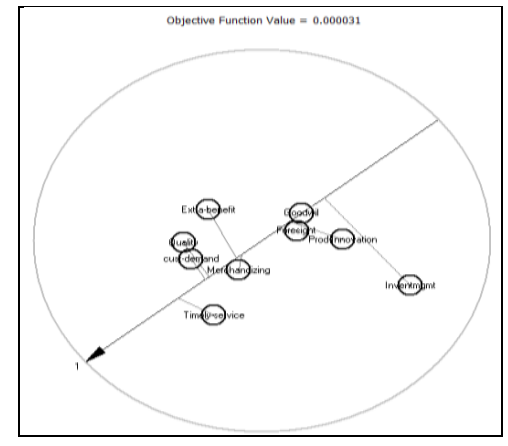

The objective function value for attribute rating for retailers with respect to customers' preference for a particular tea brand is $\mathbf{0 . 0 0 0 0 3 1}$ The priority on which Retailers keep a particular tea brand in their retail outlet is as follows: Timeliness of service, Customer Demand, Product Quality, Merchandizing, Extra Benefit, Foresight, Goodwill, Product Innovation and Inventory Management. Most important areas which needs to be focused accordingly is availability and efficient distribution network, Quality of the product is very important for any tea brand to sustain in the long run. Retailer correlate with the customers or the retailers do as per customer needs and requirements. Hence the first priority is on timeliness service of the product delivery on time (ie supply chain) should be strong and product should be as per customer preferences.

\subsection{CUSTOMER SPECIFICATIONS FOR INCREASING THE CUSTOMER VALUE TOWARDS A TEA BRAND}

Conjoint analysis means constructing and conducting particular experiments among consumers in order to model their decision making process. As the name suggests, potential customers are asked to make judgments about the attributes that affect their purchase decisions conjointly, rather than evaluate each attribute individually. Analysis allows finding out which product attributes create most value to a customer and how customers are likely to react to different product configurations. This information can lead to the creation of optimal value propositions. The research setting is made quite close to actual decision making in a real market: where the customer's task is to rank the different product alternatives which are offered to him and pick out the one that creates most value for him. Whereas ranking is based on personal preference to different attributes of every product alternative.

\subsubsection{SELECTION OF VARIABLES \& SAMPLE SIZE}


In different studies it is found that the tolerance level of a respondent is $6-8$ product attributes, depending on the motivation and product awareness of the respondent (Oppewal, Vriens, 2000). That is why the correct choice of product attributes is often considered the most demanding phase of conjoint analysis (Walley et al., 1999).

For initial identification of customer wishes different techniques are used. The easiest perhaps is to use information gained from past customer interactions. Mail questionnaires, focus groups and in-depth interviews can also be used (Chan, Wu, 2002). It has been stated that for finding out 90 $95 \%$ of all customer needs concerning a product, an experienced interviewer needs to make about 2030 in-depth interviews with customers (Griffin, Hauser, 1993). However, the majority of studies have been limited to 5-17 interviews (Pullman et al., 2002). Aaker (1997) has tackled in more detail the issue of the number of respondents.

In addition to picking out the most relevant product attributes, the examinable performance levels for every attribute have to be determined. A majority of studies have used 2-4 performance levels for every attribute (Oppeval, Vriens, 2000). Two criteria are usually kept in mind when choosing the product attributes and their performance levels (Gustafsson et al., 1999):

1. The attribute levels should describe as closely as possible the real-life situation facing customers; attributes should be closely related to those products that are available to customers.

2. It is worthwhile to include factors which are considered to be company's key competencies in gaining a competitive edge.

Based on above review of the literature 10 in-depth interviews were conducted and the following factors \& factor levels were selected

\begin{tabular}{|l|l|l|l|}
\hline Factors & Type 1 & Type 2 & Type 3 \\
\hline Variety of tea & Leaf & Dust & Blended \\
\hline Pricing & Premium & Medium & Economy \\
\hline Criterion Selection & Colour & Taste & Aroma \\
\hline Influencing Factor & Brand name & Advertising & Family Opinion \\
\hline Loyal Towards Tea Brand & Very Loyal & Somewhat Loyal & Not Loyal \\
\hline Availability & All & $\begin{array}{l}\text { Only at General Store } \\
\text { Outlets }\end{array}$ & Only in Supermarket \\
\hline Preference type of tea & Packaged Tea & Loose Tea & Tea Bags \\
\hline
\end{tabular}

In this experiment with, seven product attributes where each attribute has three performance levels the number of alternative concept cards is $3^{7}=2187$. Most researchers have used only the minimum amount of concept cards that is needed to estimate efficiently the main effect of different attributes on the dependent variable (consumer's stated purchasing preference). Normally, possible interaction effects are omitted from analysis, assuming they are not strong (Gustafsson et al., 1999). The procedure of orthogonal design(also called partial factorial planning) allows to reduce the number of combinations from 2187 to 27 using Taguchi Model (in MiniTab Software), which is enough to estimate efficiently (with sufficient reliability) the main effects.

Total respondents of 150 were selected consisting of Consumers, Retailers, Distributors, C\&F, Employees involved in the Tea Brand distribution chain to whom the Questionnaire has been administered and relevant information through 
Interview process face to face, skype and telephonic process with each was done to collect the relevant information for the research paper.

\subsubsection{RESULTS OF CONJOINT ANALYSIS}

Based on Delta value and rank attached to product attributes single performance levels have been calculated. It was found that on average the most important attribute for customers is the preference for the type of Tea (Packaged Tea, Loose tea or Tea Bags) followed by loyalty towards Tea. This result is logical because the people always prefer packaged food to loose and the packages tea in
Nagpur occupies between $65-70 \%$ of the total tea market segment. Tea is a morning stimulant and an essential indispensable factor of every household and hence people mostly don't experiment much when purchasing a Tea brand and hence Loyalty is the second factor influencing the customers. Next in importance are the influencing factor (brand name, family opinion and advertising) and pricing attributes, which form $3^{\text {rd }}$ and $4^{\text {th }}$ level of importance for customer's purchasing decision. The relative importance of the six attributes to all customers is on the individual level shown in TABLE 1 below

TABLE 1:

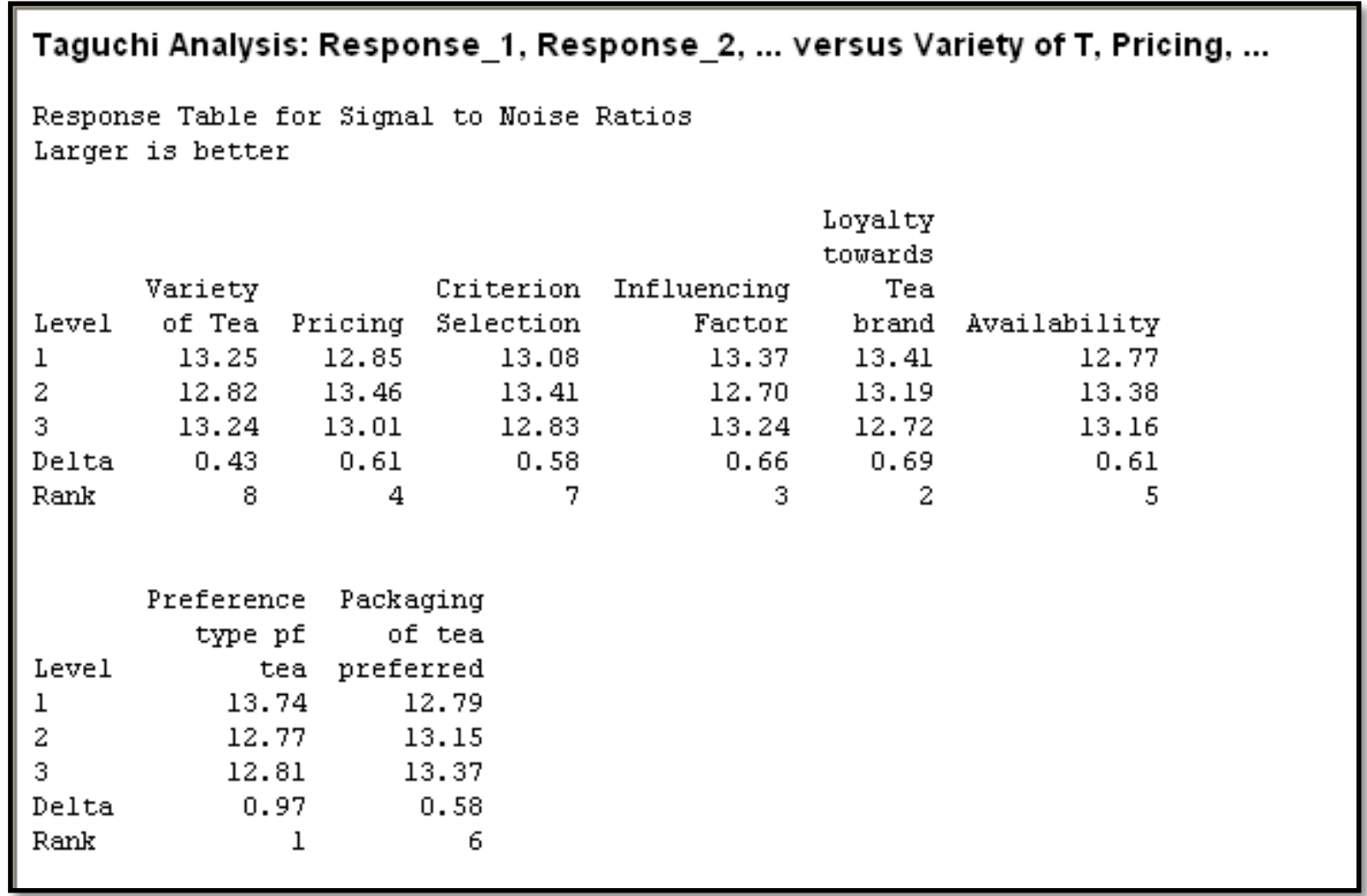

From the figure below the first influencing factor is the preference of the type of tea where packaged tea has the highest utility as it captures the maximum of Tea market in India as compared to loose or tea bags which are mostly not preferred by the consumers. Where the Company sells the convenient packs in Carton Boxes which we again see that in types of packaging carton boxes have been the most highly preferred followed by pouchs
\& Jars. As consumers are very loyal towards the Tea brand which they purchase and hence logically we can see the most important criterion or influencing factor while selection of tea is the Brand name followed by the family opinion as traditionally the family believes to have a good taste of tea which should act a stimulant and psychological preference and family preference does matter when purchasing a tea. As it is a day- 
to-day item people generally and traditionally prefer to purchase it from the General Store outlets situated close to their residence. As consumers are very loyal towards a tea brand, hence advertising does not have much influence in selection of Tea brand as also can be seen from the figure below.
The pricing fourth important factor influencing the choice of tea where High (Rs.300-400 / Kg), Medium (Rs.200-300 / Kg) and Low (Less than Rs.200/kg) where consumers prefer not premium pricing nor low pricing but medium pricing preferable for all segment of customers.

Figure 13

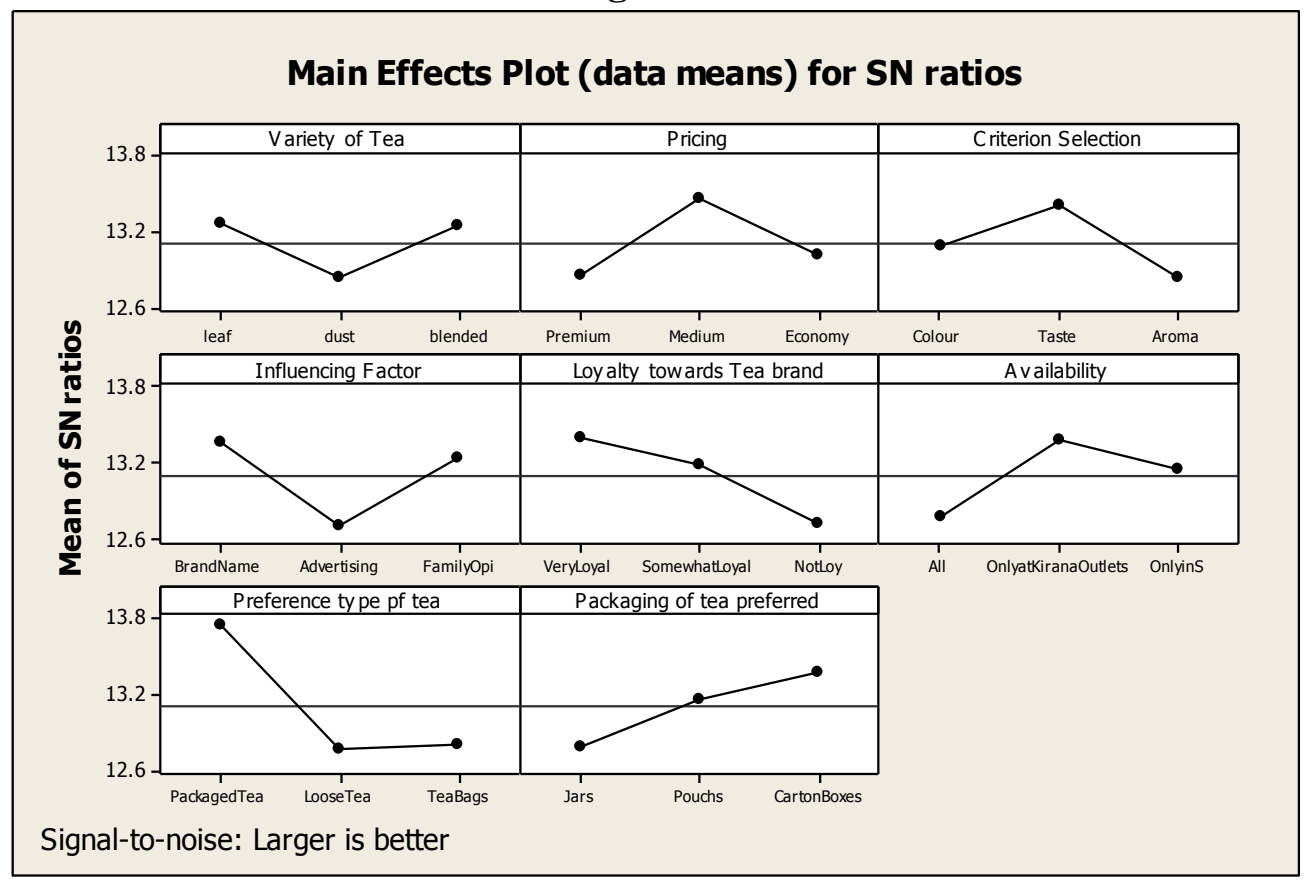

Figure 14:

Using the best fit factors - the highest response value for the combination is predicted -

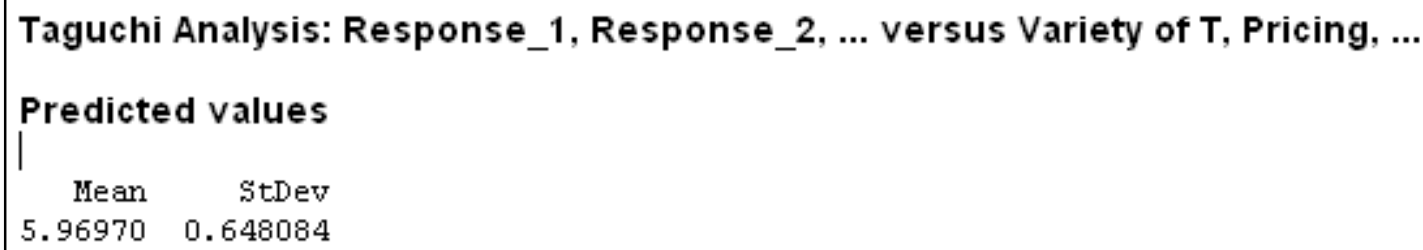




\section{The most preferred set as shown in figure above} is

Variety of tea should be leaf with medium pricing where selection criterion of tea is good taste and brand name influences the consumer the highest and Tea should preferably be present at all General Store Outlets and preferred convenient packaging for consumers is Carton Boxes.

\subsection{CART ANALYSIS}

Classification and Regression Trees (CART) give an intuitive way to model data. They can be used to construct models, but they are also very useful in exploring data. In particular, when a predictor has numerous levels, CART modelling can be used to group those levels into broader categories.

Figure 15: Regression Tree Analysis

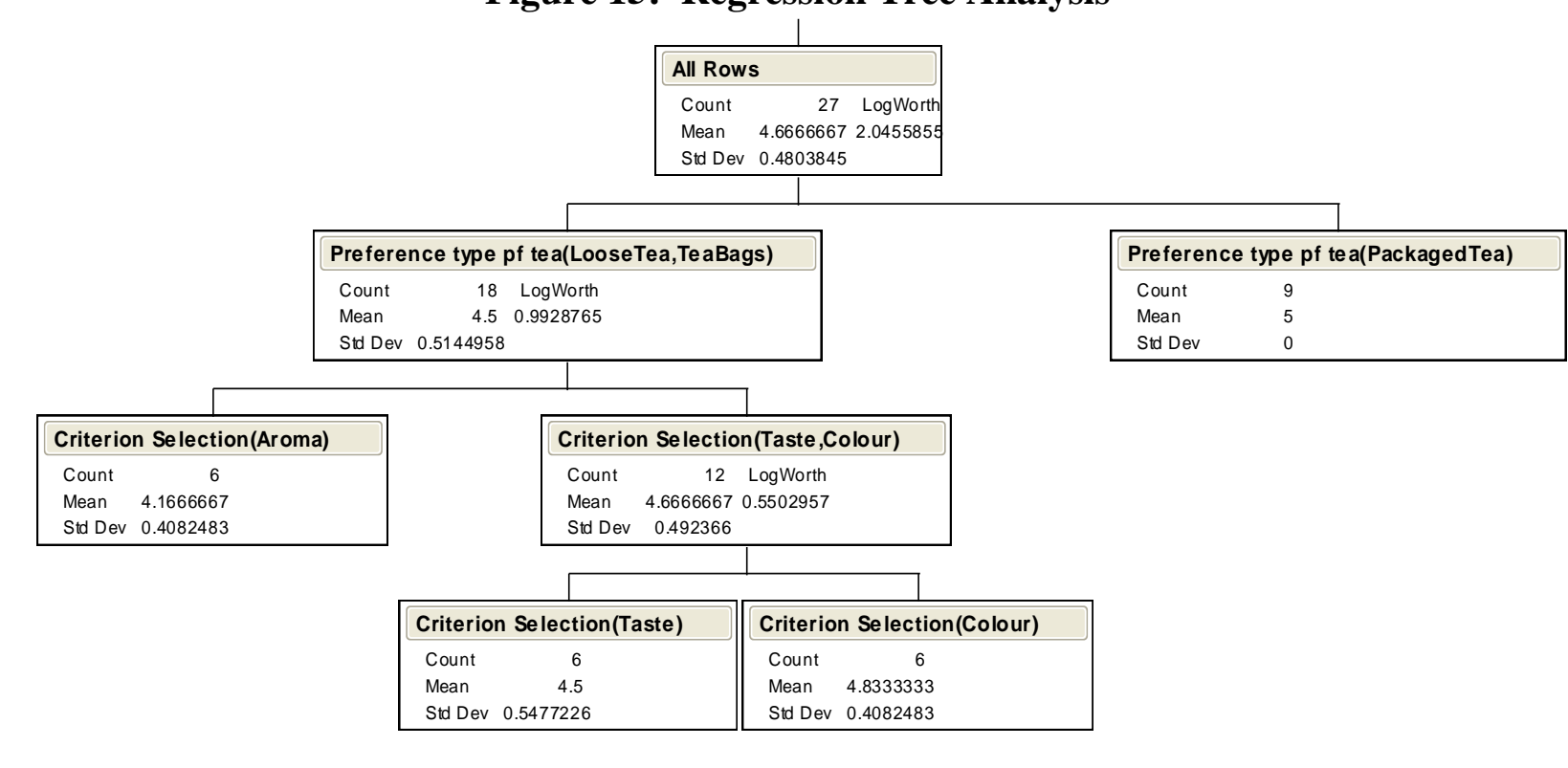

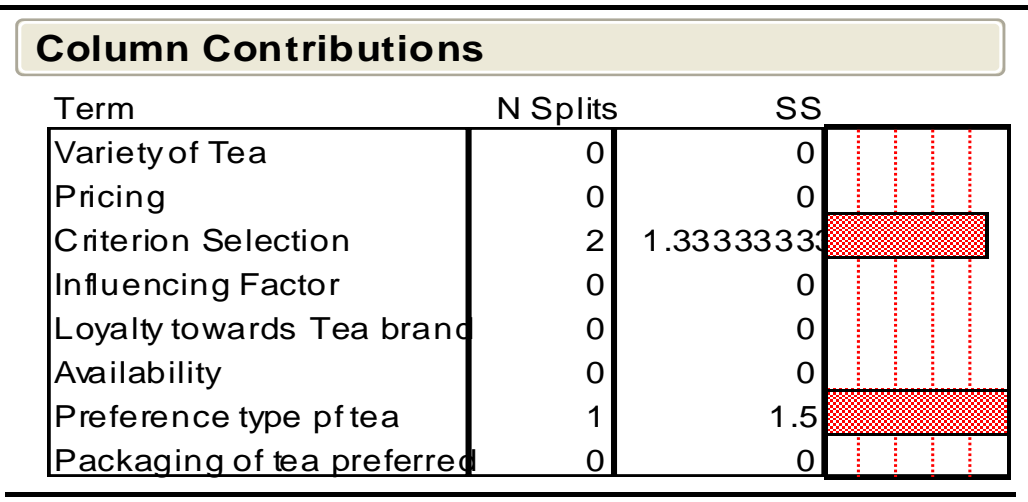

The rating given by consumers to the profile set derived from Taguchi model is used to determine the category most affecting the consumer choice for tea selection. From above we can clearly see that Criterion selection and Preference of type of tea are two most important factors effecting choice of consumers in India.

\subsection{CONCLUSION}

www.psychologyandeducation.net
As per attribute rating of the retailers Red Label is ranked first preference followed by close preference for Tata Tea and Wagh Bakri alike, the third in preference is Society and the last in preference is Double Diamond. Hence based on attribute rating we can conclude that competitive pricing, efficient and timely distribution network, promotional strategies for both consumers and retailers are driving factors for tea brands to increase the market share in India and offer tough 
competition to the top players in the Tea industry.

The priority on which customer's preference of a particular tea brand from a retail outlet is as follows: Availability, Taste, Quality, Packaging, Loyalty, Price, Brand, Colour, Content, Production and Social belonginess. The priority on which Retailers keep a particular tea brand in their retail outlet is as follows: Timeliness of service, Customer Demand, Product Quality, Merchandizing, Extra Benefit, Foresight, Goodwill, Product Innovation and Inventory Management. The most preferred combination is Variety of tea should be leaf with medium pricing where selection criterion of tea is good taste and brand name influences the consumer the highest and Tea should preferably be present at all General Store Outlets and preferred convenient packaging for consumers is Carton Boxes. Criterion selection and Preference of type of tea are two most important factors effecting choice of consumers in India.

\subsection{REFERENCES}

[1] Kotri, Andrus Analyzing Customer Value using Conjoint Analysis ; An example of a packaging company, (2006), Tartu University Press (ISSN 1406-5967)

[2] Aaker, D. A.; Kumar, V.; Day G.S. 'Marketing Research' (NY: Wiley, 1997) 756 pgs.

[3] Anderson, J.C.; Jain, D.C.; Chintagunta, P. 'Customer Value Assessment in Business Markets' Journal of Business-to-Business

[4] Smith, S.M. 'Conjoint Analysis Tutorial' [http://marketing.byu.edu/htmlpages/tutori als/conjoint.htm] 16. August. 2005

[5] Marketing, 1, 1993, pp. 4-26.Cohen, Steve, and Paul Markowitz. "Renewing Market Segmentation: Some New Tools to Correct Old Problems." ESOMAR 2002 Congress Proceedings. ESOMAR, pp. 595-612.

[6] Kotler, Philip. Marketing Management: Analysis, Planning, Implementation and Control. Prentice Hall Press, 1999.
[7] Walters, D.; Lancaster, G. 'Value-based marketing and its usefulness to customers' Management Decision, Vol. 37, No. 9, 1999, pp. 679-708.

[8] Woodall, T. 'Conceptualizing Value for Customer - Attributional, Structural and Dispo-sitional Analysis' Academy of Marketing Science Review, 12, 2003, pp. 142.

[9] Kucukemiroglu, Orsay, "Market segmentation by using consumer lifestyle dimensions and ethnocentrism - An empirical study", European Journal of Marketing Vol 33, 5/6, 1999, pp. 470487

[10] Richard Spoth, A.Dwayne Ball1, Allen Klose 1 and Cleve Redmond, "Illustration of a market segmentation technique using family-focused prevention program preference data", Health Education Research- Theory \& Practice, Vol.11 no.2 1996 pp 259-267

[11] Dolni-ar, S. (2002). Review of Data-Driven Market Segmentation in Tourism. Journal of Travel \& Tourism Marketing, 12(1), 122.

[12] Frank, R. E., Massy, W. F. and Wind, Y. (1972). Market Segmentation. Englewood Cliffs: Prentice-Hall.

[13] Wedel, M. and Kamakura, W. (1998). Market Segmentation - Conceptual and Methodological Foundations. Boston: Kluwer Academic Publishers.

[14] Bhattacherjee, A. (2001), "Understanding information systems continuance: An expectation confirmation model". MIS Quarterly, 25 (3): 351-370.

[15] Engel, J.F.; Kollat, D.T. and Blackwell, R.D. (1968), Consumer Behavior, Holt, Rinehart and Winston. 